\title{
Call for Papers for Forthcoming Special Issues
}

\author{
Child Welfare Policy and Practice: \\ Rethinking the History of our Certainties
}

Forthcoming Special Issue

Volume 14, Numbers 3/4, 1992

\author{
Rosemary Sarri and Janet Finn, Guest Editors \\ University of Michigan
}

This special issue will focus on the current problematic status of child well being in the U.S. and the critical conditions of the child welfare field. The field is characterized by accelerating rates of placement of children out of their homes, especially minority children, of institutionalized youth, of reported child abuse and neglect, and of the growing inability of child welfare agencies to meet the demands for service. The issue will offer both a retrospective and a prospective focus that will examine critically the history of policies and practices as a context for informing the development of future innovations. The development of child welfare practices are informed by certainties or accepted truths that are embedded in broader cultural understandings and that we have failed to critically examine. Among the certainties we will examine in this issue are: the dichotomy of public and private; the primacy of autonomous individualism; and the capacity of corrective intervention. These certainties constrain the formulation of critical questions about the nature of child welfare policy and practice. Added to this situation is the declining significance of community that has consequences for family and the state. The future of child welfare practice must explore a new set of critical questions that challenge these certainties if truly empowering models of practice are to be developed. Needed also are programs, policies and practices that challenge the certainties from cross-cultural, cross-gender, and cross-national perspectives. Taken together, we hope that such a collection will stimulate creative directions in professional education and action for the 21 st century. The guest editors will share with potential authors a paper that develops some of the elements of the new framework that is presented in this Call. Please contact either editor. 


\title{
Child Welfare Reform Experiments
}

Forthcoming Special Issue

Volume 14, Numbers 1/2, 1992

\author{
Douglas J. Besharov, Guest Editor \\ American Enterprise Institute
}

Papers Include:

Gordon Berlin

Reforming Child Welfare: Choosing and

Measuring Interventions.

David Fanshel

Foster Care Services for Children.

Peter Forsythe

Homebuilders and Family Preservation.

William Pierce

Adoption and Other Permanency Considerations.

Peter H. Rossi

A Strategy for Evaluating Family Preservation Programs.

John R. Schuerman

Some Realities in the Implementation of Family

Tina L. Rzepnicki

Preservation Services.

Andrea J. Sedlak

Barbara D. Goodson

National Prevalence of Child Abuse and Neglect.

Mark F. Testa

Conditions of Parents and Children at Risk of Substitute Care.

\section{Issues in Primary Prevention of Child Abuse and Neglect: Adolescent Pregnancy Life Skills}

Forthcoming Special Issue

Peggy Smith

Baylor University School of Medicine
Volume 14, Number 6, 1992

\author{
John Poertner \\ University of Kansas
}

Primary prevention of child abuse and neglect may be most effective through careful targeting of high risk groups. Adolescent parents and young unsupervised children present two susceptible target populations. As the effectiveness of prevention is difficult to document for these groups, prevention is often questioned. This special issue will address recent research critical to understanding the effectiveness of primary prevention among these two high risk populations. 